\title{
Hierarchical nanoporous nickel alloy as three-dimensional electrodes for high-efficiency energy storage
}

\author{
H.-J. Qiu, ${ }^{\mathrm{a}}{ }^{\text {Y. Ito, }}{ }^{\mathrm{a}}$ and M.W. Chen ${ }^{\mathrm{a}, \mathrm{b}, \mathrm{c}_{*}}$ \\ ${ }^{a}$ WPI Advanced Institute for Materials Research, Tohoku University, Sendai 980-8577, Japan \\ ${ }^{\mathrm{b}}$ State Key Laboratory of Metal Matrix Composites, School of Materials Science and Engineering, \\ Shanghai Jiao Tong University, Shanghai 200030, China \\ ${ }^{c}$ CREST, Japan Science and Technology Agency, Saitama 332-0012, Japan \\ *Email: mwchen@wpi-aimr.tohoku.ac.jp
}

\begin{abstract}
Hierarchical nanoporous metals with a large surface area and pore channels are the sought-after nanostructure for many applications. Here we report a two-step dealloying approach to fabricate a hierarchical nanoporous $\mathrm{Ni}$ alloy by utilizing the chemical stability difference of the constituent elements in a multicomponent precursor. Due to the large surface area and high electric conductivity, the hierarchical nanoporous $\mathrm{Ni}$ alloy exhibits a high specific areal capacitance of $\sim 1.11 \mathrm{~F} \mathrm{~cm}^{-2}$ and volumetric capacitance of $317 \mathrm{~F} \mathrm{~cm}^{-3}$.
\end{abstract}

Keywords: hierarchical structure, nanoporous metal, dealloying, supercapacitor 
Dealloyed nanoporous metals with bicontinuous open porosity have shown great promise as a new class of functional materials for a wide range of applications in catalysis, fuel cells, sensors, actuators, energy storage and so forth [1-9]. The chemical and physical properties of nanoporous metals have been found to strongly depend on the characteristic length of the porous materials, namely the nanopore and ligament sizes [10-12]. In general, a smaller pore/ligament size gives rise to a larger effective surface area, higher chemical activity and stronger localized surface plasmon resonance and thus is a desirable nanostructure for catalytic, optical and energy storage applications. However, the small pores inherently impede mass transport and thereby affect reaction kinetics when liquids, solids and gases are involved into the reactions and measurements. In practice, many applications require both small pores for large effective surface area and high chemical/physical activities, and large pore sizes for fast mass exchange. For example, in supercapacitors and batteries, nanoporous metal electrodes are preferred to have large pores $(50-100 \mathrm{~nm})$ for rapid ion diffusion and small pores for large internal surface area for charge storage. Therefore, a hierarchical porous structure with both large and small pores is essential for these applications. Two well-regulated methods have been reported to fabricate bimodal nanoporous gold. Ding and Erlebacher developed a dealloying/plating/re-dealloying strategy to create nanoporous gold with a bimodal pore size distribution [13]. In their study, pre-dealloyed nanoporous gold is used as the template for $\mathrm{Ag}$ plating. Annealing is applied to form a $\mathrm{Ag}-\mathrm{Au}$ alloy skin of the metal ligaments. The second leaching of the plated Ag results in the formation of small nanopores in the initial gold ligaments. More recently, Qi and Weissmuller reported a dealloying/annealing/re-dealloying approach to fabricate bimodal nanoporous gold by dealloying a $\mathrm{Ag}_{95} \mathrm{Au}_{5}$ alloy containing a very low concentration of gold [14]. By controlling the first-step dealloying, the consequential nanoporous alloy contains a high concentration of residual $\mathrm{Ag}(\sim 52$ at.\%). After annealing, coarsened $\mathrm{Au}-\mathrm{Ag}$ ligaments can be further dealloyed to form small pores by removing the remained Ag. Additionally, bimodal nanoporous structure can also be formed by dealloying two-phase precursors[15] and 
metallic glasses [16]. It is worth noting that that the bimodal porous structure is only achieved from noble metals, mainly gold and Palladium, because of their easy formation of nanoporous structure and high chemical stability. Although there are growing demands of low-cost nanoporous transition metals for practical applications, hierarchical nanoporous non-noble metals have not been realized so far. This is mainly owing to the poor nanopore formation ability and low chemical stability of transition metals.

In this study we develop a novel approach to fabricate a hierarchical nanoporous Ni alloy by utilizing the chemical stability difference of the constituent elements in a multicomponent precursor alloy in different electrolytes. The hierarchical nanoporous $\mathrm{Ni}$ alloy with a large internal surface, high electric conductivity and fast mass transport channels holds a great promise as threedimensional nanoporous electrodes for the applications of high efficiency energy storage.

The single-phase $\mathrm{Mn}_{70} \mathrm{Cu}_{15} \mathrm{Ni}_{15}$ precursor alloy used in this study is very ductile, similar to the binary $\mathrm{Mn}_{70} \mathrm{Ni}_{30}[17,18]$, and can be cold-rolled down to $\sim 50 \mu \mathrm{m}$ (Fig. S1 in Supplementary data), which is the common thickness of current collectors in commercial batteries and supercapacitors. Since both $\mathrm{Ni}$ and $\mathrm{Mn}$ are unstable in a high concentration acid solution [17], a weak acidic electrolyte of $1 \mathrm{M}\left(\mathrm{NH}_{4}\right)_{2} \mathrm{SO}_{4}$ was used for selectively leaching $\mathrm{Mn}$ from the $\mathrm{Mn}_{70} \mathrm{Cu}_{15} \mathrm{Ni}_{15}$ alloy (free corrosion) in the first step dealloying. The dealloyed sample has a uniform nanoporous structure with the ligament/pore size of $\sim 10 \mathrm{~nm}$ (Fig. 1a), determined by a fast Fourier transform (FFT) method [19]. The small pore size is mainly caused by the low diffusivity of $\mathrm{Ni}$ at the electrode/electrolyte interface [17]. Energy-dispersive X-ray spectroscopy (EDS) analysis shows that the nanoporous alloy contains $\sim 12$ at. $\% \mathrm{Mn}, \sim 44$ at.\% $\mathrm{Ni}$ and $\sim 44$ at.\% $\mathrm{Cu}$ (inset in Fig. 1a), indicating that the nanopore formation is mainly due to the selective leaching of $\mathrm{Mn}$. Since the Ni and $\mathrm{Cu}$ ratio keeps the same as that in the precursor alloy, the dissolution of $\mathrm{Ni}$ and $\mathrm{Cu}$ in the weak acid solution is negligible. A small oxygen peak (at $0.525 \mathrm{KeV}$ ) can also be found on the EDS 
spectrum, which indicates the formation of a thin oxidelayer due to the active nature of the nanoporous $\mathrm{Ni}-\mathrm{Cu}$ alloy. The oxygen content is $\sim 2-3$ at. \%, corresponding the formation of $\sim 5 \mathrm{wt} . \%$ oxides out of the total mass of the nanoporous alloy.

The as-dealloyed nanoporous alloy was annealed at high temperatures to enlarge the ligament and pore sizes simultaneously [10]. Figure $\mathbf{1 b}$ shows that the coarsened nanoporous structure of the nanoporous alloy annealed at $800{ }^{\circ} \mathrm{C}$ for $5 \mathrm{~min}$. The average pore/ligament size is $\sim 250 \mathrm{~nm}$, about 25 times larger than that of the as-dealloyed sample. Extending the annealing time to $20 \mathrm{~min}$, the pore/ligament size increases to $\sim 500 \mathrm{~nm}$ (Fig. 1c). The pore/ligament size can be further enlarged to $\sim 1000 \mathrm{~nm}$ after annealing at $900{ }^{\circ} \mathrm{C}$ for $20 \mathrm{~min}$ (Fig. 1d). Therefore, the nanopore/ligament size of the nanoporous $\mathrm{Ni}$ alloy can be tailored in a wide range by controlling the heat treatment conditions, similar to the nanoporous noble metals [10,20,21]. Although the significant nanopore and ligament growth takes place and there is significant volume shrinkage (the thickness decreased from 50 to 35 $\mu \mathrm{m}$ after annealed at $900{ }^{\circ} \mathrm{C}$ for $20 \mathrm{~min}$ ), the bicontinuous nanoporous structure is well retained in the entire sample as shown in the cross-sectional scanning electron microscope (SEM) image (inset in Fig. 1d). Moreover, the annealed samples have a shining color and smooth ligament surface, indicating that the hydrogen/argon protection effectively prevents the oxidation of the nanoporous $\mathrm{Ni}$ alloy at high temperatures.

In order to generate a hierarchical nanoporous structure, the annealed samples with large pores and ligaments were subjected to chemical etching in a dilute $\mathrm{HNO}_{3}$ solution $(0.8 \mathrm{M})$ to selectively leach $\mathrm{Cu}$ from the nanoporous alloy. Although $\mathrm{Cu}$ has a higher electrode potential and is electrochemically more stable than $\mathrm{Ni}$, the dilute acid solution can preferably dissolve $\mathrm{Cu}$ because of the passivation of Ni in the acid electrolyte [22, 23]. The SEM image of Figure 2a shows that the secondary pores with smaller sizes are formed within the large Ni alloy ligaments in the coarsened nanoporous Ni alloy annealed at $900^{\circ} \mathrm{C}$ for $20 \mathrm{~min}$. The zoom-out SEM image (Fig. 2b) evidences 
that the hierarchical porous structure is formed uniformly through the entire sample. The crosssectional SEM image (Fig. 2c) demonstrates that the hierarchical porous structure remains nearly the same from the center region to surface. After the secondary dealloying, the composition of the hierarchical nanoporous sample is measured to be $\mathrm{Mn}_{7} \mathrm{Cu}_{28} \mathrm{Ni}_{65}$ (at.\%) (the inset of Fig. 2c). The reduced $\mathrm{Cu} / \mathrm{Ni}$ and $\mathrm{Mn} / \mathrm{Ni}$ ratios, compared to the first-step dealloyed sample, indicate that the formation of small pores in the coarse ligaments mainly arises from the selective dissolution of $\mathrm{Cu}$ together with a small amount of $\mathrm{Mn}$. The residual $\mathrm{Cu}$ and $\mathrm{Mn}$ are most likely to be trapped inside the ligaments due to the passivation of $\mathrm{Ni}$ during the corrosion in the acid solution. Figure 2d shows the $\mathrm{N}_{2}$ adsorption/desorption isotherm of the hierarchical nanoporous Ni alloy. The surface area is calculated to be $16.8 \mathrm{~m}^{2} \mathrm{~g}^{-1}$ by Brunauer-Emmett-Teller formula. The hysteresis behavior in the $\mathrm{N}_{2}$ adsorption/desorption curve confirms the existence of secondary small pores. On the basis of Barrett-Joyner-Halenda formula [24], it is estimated that there are two types of small pores, one with the feature size of $\sim 185 \mathrm{~nm}$ and the other of $\sim 6 \mathrm{~nm}$, formed on the coarse Ni alloy ligaments. The hierarchical porosity is likely associated with the different dissolution rates of $\mathrm{Mn}$ and $\mathrm{Cu}$. The calculated pore volume is $\sim 31 \mathrm{~cm}^{3} \mathrm{~g}^{-1}$ and the porosity is as large as $\sim 71 \%$ since the overall sample size (volume) keeps constant during the secondary dealloying. Accompanying with the evolution of nanoporosity, the color of the nanoporous $\mathrm{Ni}$ alloy changes from slightly dark after first dealloying to bright white after annealing and then to dark after second dealloying, indicating the strong structure dependence of the optical properties of the nanoporous Ni alloy.

To demonstrate the potential applications of the low-cost hierarchical nanoporous $\mathrm{Ni}$ alloy in energy storage and conversion, we preliminarily utilized the sample as free-standing electrodes and current collectors of electrochemical supercapacitors. Electrochemical cyclic voltammetry (CV) characterization shows that the hierarchical $\mathrm{Ni}$ alloy has a nearly pure $\mathrm{Ni}$ surface with $\mathrm{Ni}$ oxidation (forming oxides/hydroxides) and reduction peaks at $\sim 0.45 \mathrm{~V}$ and $\sim 0.20 \mathrm{~V}$, respectively, in a $1 \mathrm{M}$ $\mathrm{KOH}$ aqueous solution (Fig. 3a), while the redox peaks from $\mathrm{Cu}$ and $\mathrm{Mn}$ are negligible. In 
comparison, the annealed nanoporous alloy with a large pore size (before second dealloying) shows obvious redox peaks from $\mathrm{Cu}$ between -0.4 and $0.1 \mathrm{~V}$, demonstrating that the residual $\mathrm{Cu}$ and $\mathrm{Mn}$ in the hierarchical nanoporous Ni alloy mainly reside in the core of the alloy ligaments. Importantly, the hierarchical sample shows a much larger integration area under the redox peaks, compared to the coarsened nanoporous alloy, suggesting higher charge storage because of the larger internal surface area and the formation of high-capacitance $\mathrm{Ni}(\mathrm{OH})_{2}$. As shown in the charge/discharge curves (Fig. 3b), there are voltage plateaus at around $0.25-0.35 \mathrm{~V}$ during charging and discharging, consistent with the redox reactions of $\mathrm{Ni}(\mathrm{OH})_{2}$ reported before $[25,26]$. The slightly longer charging time than discharging, particularly at low current densities, is probably caused by the in situ formation of pseudocapacitive Ni-based oxides/hydroxides in the alkaline solution during charging. XRD analysis (Fig. S2, Supplementary data) shows that, along with $\mathrm{Ni}(\mathrm{OH})_{2}$ peaks, a small peak at $\sim 36^{\circ}$ can also be detected, corresponding to $\mathrm{Cu}_{2} \mathrm{O}$ or mixed $\mathrm{Cu} / \mathrm{Ni}$ oxides due to the high amount of $\mathrm{Cu}$ in the alloy. The specific areal capacitance calculated from the discharge curves is shown in Figure 3c. The hierarchical nanoporous Ni alloy can reach a high areal capacitance of $\sim 1.11 \mathrm{~F} \mathrm{~cm}^{-2}$ at the current density of $1.25 \mathrm{~mA} \mathrm{~cm}^{-2}$, which is about $2-5$ times higher than recently reported $\mathrm{MnO}_{2} / \mathrm{Co}_{3} \mathrm{O}_{4}$ core-shell hybrid arrays $\left(0.71-0.4 \mathrm{~F} \mathrm{~cm}^{-2}\right.$ at $\left.4-44.7 \mathrm{~mA} \mathrm{~cm}{ }^{-2}\right)$ [27] and $\mathrm{MnO}_{2}-\mathrm{NiO}$ tubular arrays $\left(0.4-0.22 \mathrm{~F} \mathrm{~cm}^{-2}\right.$ at $\left.5-25 \mathrm{~mA} \mathrm{~cm}{ }^{-2}\right)$ [28]. With the increase of current density from 1.25 to $20 \mathrm{~mA} \mathrm{~cm}$, the specific areal capacitance still keeps a high value of $1.05 \mathrm{~F}$ $\mathrm{cm}^{-2}$ ( $95 \%$ retained), verifying the high-rate capacity performance of the hierarchical nanoporous electrode compared with most reported pseudocapactive electrodes $[3,25,29]$. The high-rate capacity performance is believed to arise from the fast electron/ion transfer of the highly conductive metal electrode with interconnected large pore channels. Although $\mathrm{Ni}$ is much heavy than active carbon, the commercial electrode material, the volumetric capacitance of the hierarchical nanoporous $\mathrm{Ni}$ alloy is calculated to be $\sim 317 \mathrm{~F} \mathrm{~cm}^{-3}$, which is also more than 3 times higher than reported pseudocapacitor electrodes and carbon materials, such as $\mathrm{NiCo}_{2} \mathrm{O}_{4} /$ carbon aerogel 
composite electrode $\left(110 \mathrm{~F} \mathrm{~cm}^{-3}\right)[30]$ and $\mathrm{MnO}_{2} /$ carbon electrode $\left(90 \mathrm{~F} \mathrm{~cm}^{-3}\right)$ [31]. Since there is only $\sim 5$ wt.\% oxides in the nanoporous alloy, the the specific capacitance per unit oxides can reach about $1900 \mathrm{~F} / \mathrm{g}$, which is close to the theoretical value of $\mathrm{Ni}(\mathrm{OH})_{2}$. It can be expected that the capacitive performance of the hierarchical porous electrode can be further improved if highcapacitance pseudocapacitive materials, such as $\mathrm{MnO}_{2}$, are deposited on the internal surface of the hierarchical nanopores. Our preliminary result also shows that the hierarchical electrode possesses excellent cycling stability. The capacitance remains to be $\sim 97 \%$ after 2000 cycles at the

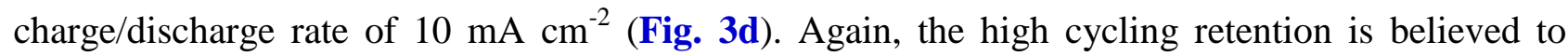
originate from the high electron/ion conductivity and mechanical stability of the hierarchical porous structure.

In summary, a hierarchical nanoporous $\mathrm{Ni}$ alloy with hierarchical porosity has been successfully fabricated by dealloying a multicomponent $\mathrm{Mn}_{70} \mathrm{Cu}_{15} \mathrm{Ni}_{15}$ alloy. By utilizing the chemical stability disparity of $\mathrm{Cu}, \mathrm{Ni}$ and $\mathrm{Mn}$ in different electrolytes, the constituent elements can be selectively dissolved at different stages of dealloying to form hierarchical nanoporosity. Moreover, the hierarchical nanoporous $\mathrm{Ni}$ alloy shows excellent pseudocapacitive performance with ultrahigh specific areal capacitance and volumetric capacitance because of the large effective area, high electric conductivity and fast ion transport. It is worth noting that the dealloying strategy developed in this study can be easily applied to other alloy systems as a general approach to fabricate hierarchical nanoporous metals and alloys for applications in sensing devices, catalysis and energy storage and conversion.

This work was sponsored by JST-CREST "Phase Interface Science for Highly Efficient Energy Utilization”, JST, Japan; "World Premier International (WPI) Research Center Initiative for Atoms, Molecules and Materials", MEXT, Japan; and Strategic Information and Communications 
R\&D Promotion Programme (SCOPE). H.J.Q. is supported by the Japan Society for the Promotion

1 of Science (JSPS) postdoctoral fellowship program (P12054).

Supplementary data associated with this article can be found. 


\section{References}

[1] A. Wittstock, V. Zielasek, J. Biener, C.M. Friend, M. Baumer, Science 327 (2010) 319.

[2] Y. Ding, M.W. Chen, J. Erlebacher, J. Am. Chem. Soc. 126 (2004) 6876.

[3] X.Y. Lang, A. Hirata, T. Fujita, M.W. Chen, Nat. Nanotechnol. 6 (2011) 232.

[4] L.F. Liu, E. Pippel, R. Scholz, U. Gosele, Nano Lett. 9 (2009) 4352.

[5] E. Detsi, P. Onck, J.T.M. De Hosson, ACS Nano 7 (2013) 4299.

[6] H.J. Jin, J. Weissmuller, Science 332 (2011) 1179.

[7] J. Snyder, T. Fujita, M.W. Chen, J. Erlebacher, Nat. Mater. 9 (2010) 904.

[8] J. Weissmuller, R.C. Newman, H.J. Jin, A.M. Hodge, J.W. Kysar, Mrs Bull 34 (2009) 577.

[9] J. Biener, A. Wittstock, L.A. Zepeda-Ruiz, M.M. Biener, V. Zielasek, D. Kramer, R.N. Viswanath, J. Weissmuller, M. Baumer, A.V. Hamza, Nat. Mater. 8 (2009) 47.

[10] L.H. Qian, X.Q. Yan, T. Fujita, A. Inoue, M.W. Chen, Appl. Phys. Lett. 90, 153120 (2007).

[11] Y. Ding, M.W. Chen, Mrs Bull 34 (2009) 569.

[12] E. Detsi, S. Punzhin, J. Rao, P.R. Onck, J.T.M. De Hosson, ACS Nano 6 (2012) 3734.

[13] Y. Ding, J. Erlebacher, J. Am. Chem. Soc. 125 (2003) 7772.

[14] Z. Qi, J. Weissmüller, ACS Nano 7 (2013) 5948.

[15] Z.H. Zhang, Y. Wang, Z. Qi, J.K. Lin, X.F. Bian, J. Phys. Chem. C 113 (2009) 1308.

[16] J.S. Yu, Y. Ding, C.X. Xu, A. Inoue, T. Sakurai, M.W. Chen, Chem. Mater. 20 (2008) 4548.

[17] H.J. Qiu, J.L. Kang, P. Liu, A. Hirata, T. Fujita, M.W. Chen, J. Power Sources 247 (2013) 896.

[18] M. Hakamada, M. Mabuchi, J. Alloy. Compd. 485 (2009) 583.

[19] T. Fujita, M.W. Chen, Jpn. J. Appl. Phys. 47 (2008) 1161.

[20] E. Detsi, M. van de Schootbrugge, S. Punzhin, P.R. Onck, J.T.M. De Hosson, Scripta Mater. 64 (2011) 319.

[21] E. Detsi, S. Punzhin, P.R. Onck, J.T.M. De Hosson, J. Mater. Chem. 22 (2012) 4588.

[22] J.K. Chang, S.H. Hsu, I.W. Sun, W.T. Tsai, J. Phys. Chem. C 112 (2008) 1371.

[23] L. Sun, C.L. Chien, P.C. Searson, Chem. Mater. 16 (2004) 3125.

[24] E.P. Barrett, L.G. Joyner, P.P. Halenda, J. Am. Chem. Soc. 73 (1951) 373.

[25] J. Ji, L.L. Zhang, H. Ji, Y. Li, X. Zhao, X. Bai, X. Fan, F. Zhang, R.S. Ruoff, ACS Nano 7 (2013) 6237.

[26] J.L. Kang, A. Hirata, H.J. Qiu, L.Y. Chen, X.B. Ge, T. Fujita, M.W. Chen, Adv. Mater. 00 (2013) 1.

[27] J.P. Liu, J. Jiang, C.W. Cheng, H.X. Li, J.X. Zhang, H. Gong, H.J. Fan, Adv. Mater. 23 (2011) 2076.

[28] J.P. Liu, J. Jiang, M. Bosman, H.J. Fan, J. Mater. Chem. 22 (2012) 2419.

[29] J. Jiang, Y.Y. Li, J.P. Liu, X.T. Huang, C.Z. Yuan, X.W. Lou, Adv. Mater. 24 (2012) 5166.

[30] H.C. Chien, W.Y. Cheng, Y.H. Wang, S.Y. Lu, Adv. Funct. Mater. 22 (2012) 5038.

[31] A.E. Fischer, K.A. Pettigrew, D.R. Rolison, R.M. Stroud, J.W. Long, Nano Lett. 7 (2007) 281. 
Figure captions:

Figure 1. SEM images of np-NiCu before (a) and after annealing under different conditions $\left(800^{\circ} \mathrm{C}\right.$, $5 \min (\mathrm{b}) ; 800{ }^{\circ} \mathrm{C}, 20 \mathrm{~min}(\mathrm{c}) ; 900{ }^{\circ} \mathrm{C}, 20 \mathrm{~min}(\mathrm{~d})$ ). Inset in (a) is the EDS spectrum of this sample and inset in (d) is the section-view SEM image with the scale bar of $5 \mu \mathrm{m}$.

Figure 2. (a) SEM image of the hierarchical nanoporous Ni alloy. (b) Zoom-out SEM image showing the uniformity of hierarchical structure through the entire sample. (c) Cross-sectional SEM image of the hierarchical nanoporous $\mathrm{Ni}$ alloy. Inset in (c) shows the EDS spectrum of the hierarchical alloy and (d) the hysteresis curve of $\mathrm{N}_{2}$ adsorption/desorption isotherm of the hierarchical nanoporous Ni alloy (the $\mathrm{X}$-axis was normalized with the vapor pressure of nitrogen $\left(\mathrm{P}_{0}\right)$ at $77.0 \mathrm{~K}(0.101 \mathrm{MPa}))$.

Figure 3. (a) CV curves of the annealed nanoporous Ni alloy before and after the second dealloying, scan rate: $40 \mathrm{mV} \mathrm{s}^{-1}$. (b) Charge-discharge curves of the hierarchical electrode after the second dealloying. (c) Rate dependence of the specific areal capacitance of the hierarchical electrode at different current densities and (d) the capacitance retention as a function of cycle number at a constant charge/discharge current density of $10 \mathrm{~mA} \mathrm{~cm}^{-2}$. The electrolyte is $1 \mathrm{M} \mathrm{KOH}$ aqueous solution. 

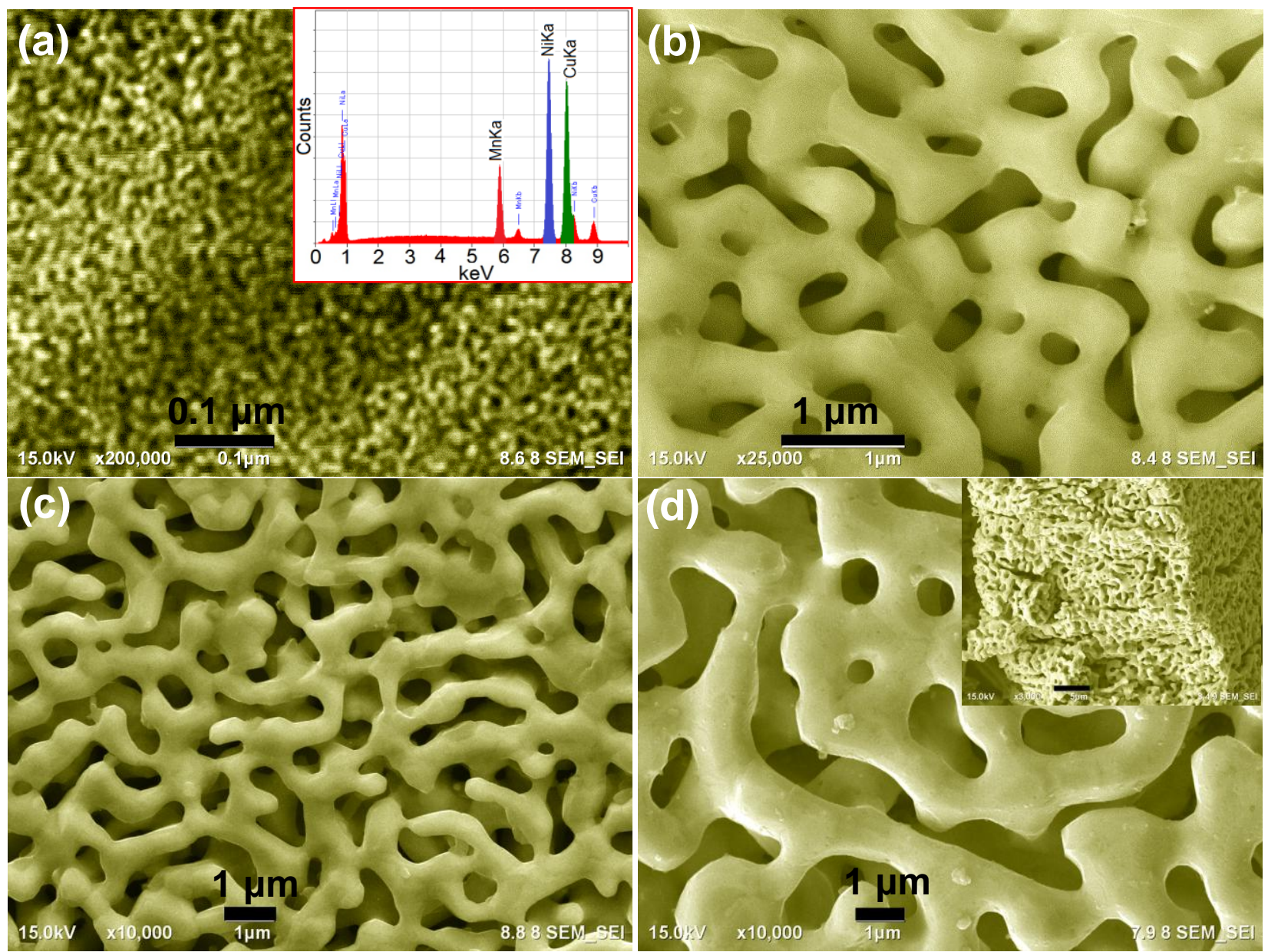

Figure 1. 

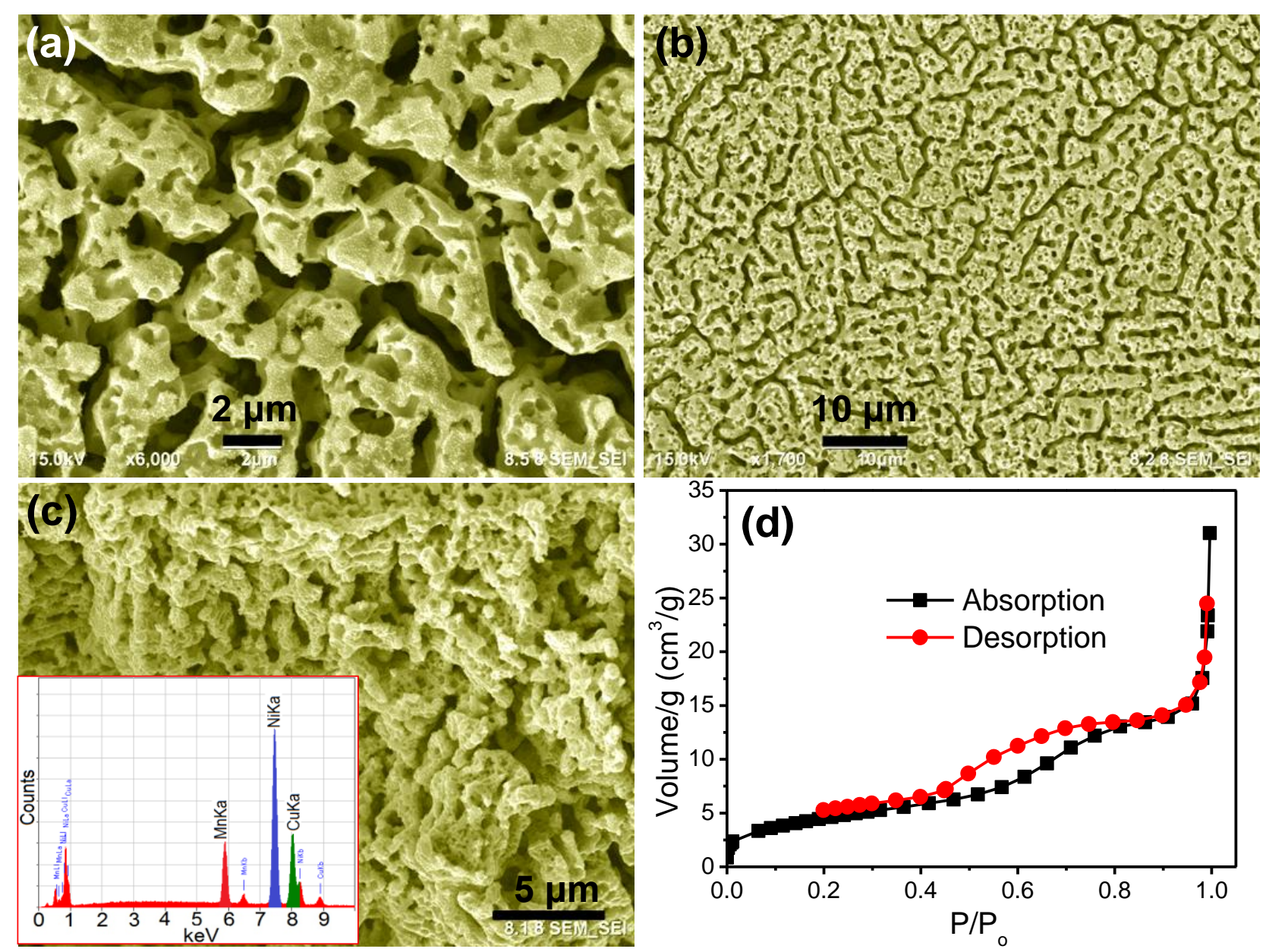

Figure 2. 

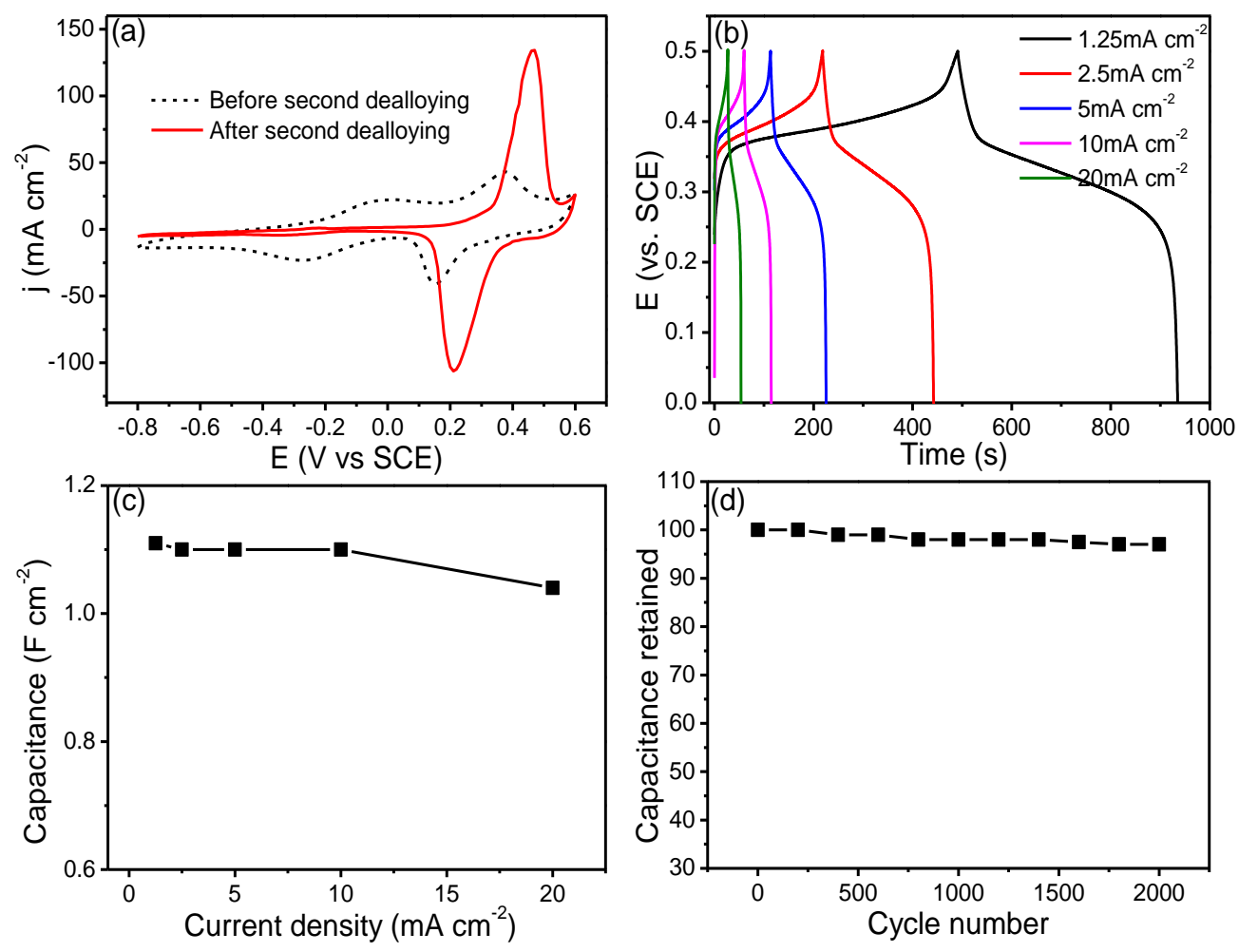

Figure 3. 